\title{
Gestión municipal en el desarrollo local de la provincia de Mariscal Cáceres
}

\section{RESUMEN}

Luis Israel Bravo Vilela lbravov@ucvvirtual.edu.pe arq.israelbravo@gmail.com

Dr. Keller Sánchez Dávila ksanchezd@ucv.edu.pe

Universidad César Vallejo Tarapoto - Perú

En este estudio se propuso como objetivo conocer el nivel de eficiencia de la gestión municipal en el desarrollo local de la provincia de Mariscal Cáceres en los últimos cinco años. El estudio es básico, el diseño es la revisión sistemática; la búsqueda sistemática y bibliográfica de documentos se realizó en los buscadores: BASE, Scielo y Google Académico, el periodo fue del 2017 hasta el año 2021, finalmente fueron seleccionados 21 artículos que guardan relación con el tema abordado, para ello se usó como técnica la revisión documental. Luego del análisis de los resultados y las conclusiones obtenidas de acuerdo a los objetivos de la revisión sistemática, se ha determinado que las investigaciones que más predominan han sido las de tipo básico, enfoque cualitativo y diseño descriptivo. Por otra parte, estos se encuentran organizados desde diferentes realidades gubernamentales, entre ellas con mayor relevancia del contexto Latinoamericano. Vale precisar que los estudios guardan correlación con la perspectiva de las necesidades involucradas en el concepto de la gestión municipal. En cuanto a la variable en estudio, se puede sinterizar que la gestión pública se presenta como un actor o elemento importante del cambio local, siendo emblemática para la comprensión de obstáculos y perspectivas de desarrollo. El principal objetivo de los gobiernos municipalidades o locales es la creación de las aptitudes que faciliten la satisfacción de las prioridades de sus pobladores y asegurar así el bienestar social, económico cultural de las distintas comunidades, No obstante, la evaluación del desempeño de las actividades municipales sigue siendo compleja, puesto que buscar estándares de gestión local y establecimiento de políticas públicas y prestación de servicios, en la realidad, no es una tarea fácil.

Palabras clave: gestión municipal; desarrollo local; políticas públicas; presupuesto. 


\title{
Municipal management in the local development of the province of Mariscal Cáceres
}

\begin{abstract}
In this study it was proposed as a goal to know the level of efficiency of municipal management in the local development of the province of Mariscal Cáceres in the last five years. The study is basic, the design is the systematic review; the systematic and bibliographic search of documents was made in the search engines: BASE, Scielo and Google Scholar, the period was from 2017 to 2021, Finally, 21 articles were selected that are related to the topic addressed, for this the documentary review was used as a technique. After the analysis of the results and the conclusions obtained according to the objectives of the systematic review, it has been determined that the most prevalent investigations have been those of basic type, qualitative approach and descriptive design. On the other hand, these are organized from different governmental realities, among them with greater relevance of the Latin American context. It should be noted that the studies are correlated with the perspective of the needs involved in the concept of municipal management. As for the variable under study, it can be synthesized that public management is presented as an important actor or element of local change, being emblematic for the understanding of obstacles and perspectives of development. The main objective of municipal or local governments is the creation of skills that facilitate the satisfaction of the priorities of their inhabitants and thus ensure the social, economic and cultural well-being of the different communities, However, the evaluation of the performance of municipal activities remains complex, since the search for standards of local management and the establishment of public policies and service delivery is not, in reality, an easy task.
\end{abstract}

Keywords: municipal management; local development; public policies; budget.

Artículo recibido: 18. Julio. 2021 Aceptado para publicación: 08. Agosto. 2021 Correspondencia: 1bravov@ucvvirtual.edu.pe Conflictos de Interés: Ninguna que declarar 


\section{INTRODUCCIÓN}

La gestión realizada por la municipalidad facilita la concertación a nivel social como una práctica política que relaciona fluidamente la sociedad civil y al Estado; de ahí que, el consenso y la cultura de diálogo permita la creación de herramientas y mecanismos pertinentes para la resolución de conflictos y controversias sociales. En este sentido, a través de la presente investigación se propone la ejecución de una revisión sistemática respecto a la efectividad de la gestión realizada por la municipalidad en cuanto al desarrollo de la localidad, mediante la exploración de diversos buscadores académicos, los mismos que proporcionaran información fiable y actualizada sobre la temática (Cordero, 2018).

El desarrollo local, actualmente, se ha transformado en una estrategia idónea para contribuir con el progreso de territorios subnacionales en el contexto de la superación de los problemas fundamentales que reflejan una afectación a las instituciones públicas locales, su significación exige a las autoridades competentes al planteamiento de objetivos dirigidos a la superación de dicha problemática social en la realización de un trabajo en conjunto y planificando fines, lineamientos los que serán empleados como indicador a los gobiernos subnacionales para aventajar las características condiciones de los ciudadanos, en base, en una serie de indicadores relacionados a aspectos sociales, económicos, ambientales e institucionales (Díaz y Fernández,2020).

Como señala López, Ayala y Arellanes (2017), en la experiencia de naturaleza descentralizadora de distintos estados, denominados actualmente como países del primer mundo, se ha considerado al desarrollo de las capacidades como un aspecto primordial en gobernabilidad política, implementando con éxito las Agencias gubernamentales, conocidos como municipios, cuyo desempeño favorable obedecía a las capacidades locales de sus funcionarios y autoridades.

Tal es así que, en Gran Bretaña, Estados Unidos, Nueva Zelandia, Australia, Finlandia, Suecia, Dinamarca, Noruega, Holanda y Suiza, fijaron su interés en el fortalecimiento de una cultura adquirida de control, expresada en asesoría y acompañamiento permanente y constante del proceso relacionado a la transferencia de capacidades. Por su parte, Gran Bretaña sentó el reporte público de desempeño, a manera de mecanismo de control para viabilizar el logro de los términos de referencia adecuados de las contrataciones; por otro lado, Australia, los Estados Unidos, Finlandia, Canadá y 
Suecia, incluyeron en el proceso de gasto-presupuesto, la información de desempeño; además, los Estados Unidos, Australia y Noruega incorporaron en su proceso de planificación, la medición de desempeño (Polanco y Caballero, 2020).

Así también, las transformaciones que resultan como producto de los procesos referidos a la descentralización han provocado en Latinoamérica y en el mundo, serias modificaciones en la actuación que ejercen las instituciones municipales como parte del gobierno de las ciudades. El Estado, en su proceso de modernización, ha ocasionado que, lo mencionado sea el origen de tales reformas. El traspaso de recursos y atribuciones, además del fomento del empoderamiento como parte de su función como gestor de desarrollo, demandan cambio creciente por parte de la organización municipal respecto a la gestión interna con la finalidad que, dicha gestión esté direccionada a la satisfacción de los desafíos modernos (Cordero, 2018).

En México, de la misma forma que en numerosos estados de Latinoamérica, la aptitud de los gobiernos locales para llevar a cabo la conducción del logro, con eficiencia, incluyente y eficacia, se ha visto limitada por distintos factores, tales como la carencia de atribuciones, los insuficientes recursos referidos al presupuesto, las capacidades técnicas deficientes, además de, la carencia de una clara orientación respecto al desarrollo a nivel local. Es así que, en la realidad práctica, el funcionamiento de los gobiernos locales ha estado influenciada significativamente por los gobiernos centrales (López, Ayala y Arellanes, 2017).

En palabras de Montecinos y Contreras (2019), uno de los principales aspectos que permiten la promoción del desenvolvimiento local, es espacios subnacionales como las municipalidades es tener en cuenta las potencialidades y características de los agentes sociales, entre los que tenemos: empresas, gobierno, organizaciones productivas y civiles, centros educativos, etc., que están comprometidos de forma articulada, en la valoración de la realidad problemática, así como en la implementación adecuada de acciones dirigidas a promover el progreso de la condición en la que residen los pobladores.

Por otra parte, en Perú, el Estado ha experimentado diversas reformas en el ámbito administrativo como parte del denominado, proceso de modernización. Una de las reformas, más relevantes, en ámbito administrativo fue lo relacionado a la creación de gobiernos locales a través de la ley de descentralización; dicha ley expresa la 
importancia de una generación con autonomía política y económica más significativa por parte de los gobiernos para garantizar la promoción y el logro de un desarrollo adecuado de un territorio determinado.

Para la comprensión de la gestión municipal o local, debe entenderse que toda organización está supedita a la normativa interna del estado al que pertenecen en el ámbito constitucional, y además, a la normativa relativa a los gobiernos locales; empero, para que éstos, conforme a los aspectos específicos de gestión deben llevarse a cabo mediante la aplicación de instrumentos guías de la gestión en el contexto moderno; de ahí que, el Proyecto Estratégico Institucional, facilita la priorización y el ordenamiento de la gestión de las instituciones privadas y públicas, sin embargo, respecto a las municipalidades, éstas deben, para su creación y funcionamiento, considerar en su totalidad, los actores gubernamentales y sociales de la comunidad en las que concurren la axiología y la filosofía que establezca la característica o el modelo, debido a que, la misión y visión y de los niveles valorativos que impulsan la interacción e interrelación de los pobladores y agentes de la comunidad (Polanco y Caballero, 2020).

Por lo expuesto el estudio presente establece como la provincia de Mariscal Cáceres, en el que el principal problema expuesto se basa respecto a si el proceso de gestión municipal, evidencia relación alguna con las estrategias referidas a la intervención realizada por el gobierno para impulsar el desarrollo local y, si por medio de los servicios ofrecidos y el establecimiento de las políticas públicas se está produciendo un impacto significativo en la población, o, cuando menos en la impresión de complacencia con las tácticas planteadas por el gobierno, o, contrariamente, son consecuencia de la determinación de los representantes de la localidad. El fracaso de algunas prácticas realizadas por la gestión municipal y, sumándole, el manejo inadecuado de los recursos provenientes del Estado, han supuesto un debilitamiento en la institucionalidad de los gobiernos que, trataba de lograr una consolidación por los últimos años.

En ese contexto, diversas manifestaciones han sido observadas y se ha determinado que éstas no corresponden a las actuales exigencias para lograr el progreso local basado en la gestión realizada por la municipalidad, lo que se puede extraer lo siguiente: un aprovechamiento deficiente de las capacidades que dispone la provincia de Mariscal Cáceres, así como la gestión municipal carente de efectividad para el alcance de una 
gestión participativa e integrada que sea favorable para el progreso del aspecto económico de la localidad. Adicionalmente, una visión carente de forma sistemática en la ejecución, planificación, mejora y control del logro a nivel local. Por último, pero no menos importante la deficiente intervención de los sujetos involucrados en las fases llevadas a cabo en las gestiones de la municipalidad. Cabe señalar que, si, esto continúa de esta manera, se produce el riesgo de incurrir en una crisis sobre la gobernabilidad, de ahí que, es primordial que, los gobiernos dispongan de estrategias que viabilicen el desarrollo de la localidad que son más integrales y que garantice un beneficio para los ciudadanos.

Tomando en cuenta que la gestión implica mucho más que la mera organización, planificación, entre otras cuestiones, puesto que, los responsables de los gobiernos municipales son elegidos mediante la votación democrática y popular y entre las expectativas se considera que éstos conozcan la problemática social no solo de la localidad sino de toda la jurisdicción; de ahí que, dicha gestión debe estar articulada con concordancia con sus funciones que se relacionan de forma directa y de aquellas funciones que conllevan una realización en conjunto con el resto de otras organizaciones representativas gubernamentales del país en la localidad.

\section{Formulación del problema}

- El problema planteado es el siguiente: ¿Cuál es el nivel de eficiencia de la gestión municipal en el desarrollo local de la provincia de Mariscal Cáceres en los últimos cinco años?

Como objetivo de estudio, se propuso: Conocer el nivel de eficiencia de la gestión municipal en el desarrollo local de la provincia de Mariscal Cáceres en los últimos cinco años.

\section{MATERIAL Y MÉTODOS}

\section{Diseño de estudio}

El estudio es básico, la que permita la adquisición de conocimientos nuevos y el incremento de los mencionados mediante la revisión de la literatura de diversas investigaciones realizadas anteriormente, sin tener en cuenta la aplicación de tales como la primordial, sino por el beneficio de producir un conocimiento nuevo (Zorrilla, 1993).

El diseño de investigación es la revisión sistemática; esta constituye un estudio observacional, integrativo, secundario, retrospectivo, en ella se acoplan estudios que 
analizan la misma pregunta. De esta manera, la revisión sistemática suministra una síntesis de carácter racional de la investigación básica. Incrementa las limitaciones de la revisión mediante la aplicación de rigurosos estándares a la investigación secundaria (en ella el patrón de estudio se basan en otros estudios relacionados a la investigación) como si fueran a aplicarse a estudios de investigación primaria, es decir, los estudios originales (Beltrán, 2005).

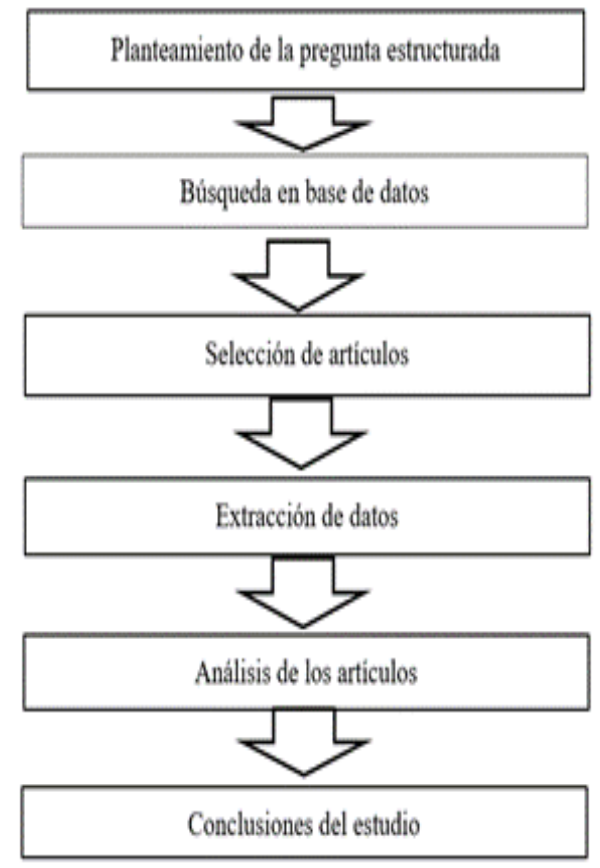

Figura. Diseño de la revisión sistemática

\section{Procedimiento de recolección de datos}

Se efectuó una búsqueda sistemática y bibliográfica de documentos en las bases de datos siguientes: BASE, Scielo y Google Académico (en el orden que se indica). La búsqueda y selección de los artículos inició en el periodo 2017 hasta el año 2021.

Respecto a la selección de los artículos, se procedió a través de una organizada estructura, que, en primer lugar, consistió en la elección de los mismos en función de la revisión del resumen, título, además de palabras empleadas para la búsqueda del artículo, así como a verificación de congruencia entre los criterios de inclusión que han fueron establecidos.

Las palabras empleadas para la búsqueda fueron colocadas teniendo en cuenta el idioma, lo que facilitaría la búsqueda en las bases de datos específicas, además se utilizó el filtro para la obtención de resultados en un periodo determinado de tiempo. Los 
términos o palabras empleadas para la realización de la búsqueda fueron: "gestión municipal” / "desarrollo local” / "municipal management". En segundo lugar, se realizó una lectura de los seleccionados artículos que obedecían a los criterios de inclusión.

Se obtuvo 79 artículos de texto completo que fueron estimados para analizar su elegibilidad. Excluyendo aquellos artículos cuyo tema trataba sobre desarrollo local y gestión municipal. Resultando de lo anteriormente expuesto se quedó con 21 artículos.

\section{Criterios de inclusión}

- Los criterios de inclusión para determinar los artículos de la revisión sistemática presente y en relación del interés abordado, consistió en; estudios que fueron publicados entre enero del 2017 y mayo del 2021. Además, tales estudios exponen variables correlacionadas a gestión municipal y desarrollo local.

- Que los estudios hayan sido publicados en inglés o español.

\section{Criterios de exclusión}

- Se excluyeron los artículos que no fueran de carácter científico o cuyos textos hayan estado incompletos. Además, no fueron considerados los artículos cuyo propósito fundamental haya sido la validación de un instrumento de medición o que se hayan tratado de estudios cualitativos o revisiones sistemáticas exclusivamente.

\section{Técnicas de análisis de datos}

- En este trabajo se utilizó la técnica de revisión documental, la cual se manejó para revisar investigaciones referentes a la gestión municipal permitiendo un mejor recojo de datos.

- Como instrumento se utilizó fichas de recolección de datos de artículos científicos lo cual nos permitió un registro de base de datos de investigaciones, este instrumento es fundamental debido a que facilita el acceso a la información que se necesita para la resolución del problema.

- La revisión documental consideró artículos de investigación en el ámbito internacional y nacional, cuya prioridad fue conocer el nivel de eficiencia de la gestión realizada por los gobiernos municipales sobre los logros de la localidad. Se consideró pertinente la inclusión de los artículos más importantes, según la evidencia que presentaron, excluyéndose los que no cumplieron con los criterios establecidos. 


\section{RESULTADOS}

En este estudio, los resultados se presentan haciendo uso de tablas, en las cuales son presentados los artículos pertenecientes a las revistas seleccionadas por su relación con la materia de análisis, en las tablas se recoge la principal información de cada uno de estos artículos, así se tiene: 
Tabla 1. Estudios revisados sobre gestión municipal

\begin{tabular}{|c|c|c|c|c|}
\hline \multicolumn{5}{|c|}{ DATOS DE LA PUBLICACIÓN } \\
\hline 1. Autor & Año & Nombre de la Investigación & $\begin{array}{c}\text { Revista donde su ubica la } \\
\text { publicación }\end{array}$ & $\begin{array}{l}\text { Volumen y } \\
\text { número }\end{array}$ \\
\hline $\begin{array}{l}\text { Álvarez, N. y } \\
\text { Delgado, J. }\end{array}$ & 2020 & Desarrollo organizacional en la gestión municipal & $\begin{array}{c}\frac{\text { https://www.ciencialatina.org/index. }}{\mathrm{php} / \text { cienciala/article/view/133/153 }} \\
\text { Ciencia Latina Revista } \\
\text { Multidisciplinaria }\end{array}$ & $4(2)$ \\
\hline
\end{tabular}

\section{CONTENIDO DE LA PUBLICACIÓN}

\begin{tabular}{|c|c|c|c|c|}
\hline $\begin{array}{l}\text { Tipo y Diseño de } \\
\text { Investigación }\end{array}$ & $\begin{array}{c}\text { Población y } \\
\text { Muestra }\end{array}$ & Instrumentos & $\begin{array}{l}\text { Aspectos } \\
\text { éticos }\end{array}$ & Resultados \\
\hline Descriptiva simple & $\begin{array}{l}10 \text { artículos } \\
\text { científicos }\end{array}$ & Encuesta & -Ninguno. & $\begin{array}{l}\text { El } 50 \% \text { de los artículos científicos están } \\
\text { centrados en el desarrollo de habilidades y } \\
\text { competencias a través de las capacidades, } \\
30 \% \text { se encuentra enfocado al empleo de } \\
\text { las TIC, para facilitar la gestión y, por } \\
\text { otro lado, el } 20 \% \text { aduce la utilización de } \\
\text { metodologías y coeficiencias empleadas } \\
\text { al mapeo de los fines institucionales. }\end{array}$ \\
\hline
\end{tabular}

al mapeo de los fines institucionales.

Conclusión
La gestión de las
municipalidades son deficientes
en Asia, Europa y África, las
autoridades y directivos de los
municipios deben tomar en
cuenta diferentes metodologías
para el desarrollo de las
organizaciones. Así mismo, en
el futuro desarrollo de
investigaciones disponer de
dimensiones y variables de
gestión que faciliten indagar con
un énfasis más significativo en
la problemática por la que
atraviesan los gobiernos locales.




\section{DATOS DE LA PUBLICACIÓN}

\begin{tabular}{|c|c|c|c|c|}
\hline Autor & Año & Nombre de la Investigación & $\begin{array}{c}\text { Revista donde su ubica la } \\
\text { publicación }\end{array}$ & $\begin{array}{l}\text { Volumen y } \\
\text { número }\end{array}$ \\
\hline \multirow[t]{2}{*}{ Arevalo, F. } & 2020 & $\begin{array}{l}\text { Evaluación según modernización del Estado en la gestión } \\
\text { municipal, } 2020\end{array}$ & $\begin{array}{l}\text { https://ciencialatina.org/index.php/ci } \\
\text { enciala/article/view/131?articlesByS }\end{array}$ & $4(2)$ \\
\hline & & & $\begin{array}{l}\text { Ciencia Latina Revista Científica } \\
\text { Multidisciplinar }\end{array}$ & \\
\hline
\end{tabular}

\begin{tabular}{|c|c|c|c|c|c|}
\hline \multicolumn{6}{|c|}{ CONTENIDO DE LA PUBLICACIÓN } \\
\hline $\begin{array}{l}\text { Tipo y Diseño de } \\
\text { Investigación }\end{array}$ & $\begin{array}{l}\text { Población y } \\
\text { Muestra }\end{array}$ & Instrumentos & $\begin{array}{l}\text { Aspectos } \\
\text { éticos }\end{array}$ & Resultados & Conclusión \\
\hline $\begin{array}{l}\text { Diseño descriptivo } \\
\text { con revisión } \\
\text { sistemática }\end{array}$ & 10 artículos & Entrevista & -Ninguno. & $\begin{array}{l}\text { El } 100 \% \text { de los estudios relacionados a la } \\
\text { evaluación según modernización del } \\
\text { Estado reconocen las bondades y } \\
\text { beneficios en el contexto de la gestión } \\
\text { púbica, como consecuencia a que la } \\
\text { evaluación solicita un compromiso a nivel } \\
\text { institucional, condiciones, políticas y } \\
\text { consecuencias; y se determina que el } \\
\text { proceso de evaluación genera un impacto } \\
\text { relación con la gestión distinta en } \\
\text { diferentes países del mundo }\end{array}$ & $\begin{array}{l}\text { El } 80 \% \text { refiere que la evaluación } \\
\text { es importante para la gestión } \\
\text { pública en el marco de la } \\
\text { modernización del Estado, ya } \\
\text { que facilita la determinación de } \\
\text { funciones, condiciones, } \\
\text { intervención conveniente y } \\
\text { sobre la elección de decisiones } \\
\text { para cumplir objetivos y metas } \\
\text { institucionales. }\end{array}$ \\
\hline
\end{tabular}




\section{DATOS DE LA PUBLICACIÓN}

\begin{tabular}{|c|c|c|c|c|}
\hline Autor & Año & Nombre de la Investigación & $\begin{array}{c}\text { Revista donde su ubica la } \\
\text { publicación }\end{array}$ & Volumen y número \\
\hline $\begin{array}{l}\text { Quispe, } \\
\begin{array}{l}\text { Ayaviri, } \\
\text { Maldonado, }\end{array} \\
\text { R. }\end{array}$ & 2018 & $\begin{array}{l}\text { Participación de los actores en el desarrollo } \\
\text { local en entornos rurales }\end{array}$ & $\begin{array}{l}\text { https://dialnet.unirioja.es/servlet/art } \\
\underline{\text { iculo?codigo }=7025048} \\
\text { Revista de Ciencias Sociales }\end{array}$ & $24(3)$ \\
\hline
\end{tabular}

\begin{tabular}{|c|c|c|c|c|c|}
\hline \multicolumn{6}{|c|}{ CONTENIDO DE LA PUBLICACIÓN } \\
\hline $\begin{array}{l}\text { Tipo y Diseño de } \\
\text { Investigación }\end{array}$ & $\begin{array}{l}\text { Población y } \\
\text { Muestra }\end{array}$ & Instrumentos & $\begin{array}{l}\text { Aspectos } \\
\text { éticos }\end{array}$ & Resultados & Conclusión \\
\hline $\begin{array}{c}\text { básica- } \\
\text { Cuantitativo- } \\
\text { explicativo }\end{array}$ & $\begin{array}{c}\text { Nueve } \\
\text { comunidades de la } \\
\text { Cuenca }\end{array}$ & Encuesta & -Ninguno. & $\begin{array}{l}\text { El logro de la localidad suscitado en las } \\
\text { comunidades rurales, primordialmente, } \\
\text { depende de las personas involucradas en } \\
\text { la localidad y gestores tales como el } \\
\text { Gobierno Municipal Autónomo, la } \\
\text { iglesia, las instituciones educativas, } \\
\text { municipales, organismos no } \\
\text { gubernamentales, organizaciones } \\
\text { sindicales, centros de salud, } \\
\text { asociaciones, productores y población; } \\
\text { en la gestión, acción y planeamiento en } \\
\text { procesos y formas de desarrollo. }\end{array}$ & $\begin{array}{l}\text { Se evidencia un significativo } \\
\text { rango de intervención por parte de } \\
\text { los actores de las localidades } \\
\text { involucrados en los proyectos } \\
\text { productivos y sociales, así mismo, } \\
\text { respecto a la intervención de los } \\
\text { pobladores, direcciona a } \\
\text { identificar escenarios distintos y } \\
\text { espacios para el logro del } \\
\text { desarrollo local; debido a que los } \\
\text { agentes y actores de desarrollo son } \\
\text { los que resuelven los procesos de } \\
\text { desarrollo, lo modos de } \\
\text { producción y el bienestar } \\
\text { comunitario del contexto rural. }\end{array}$ \\
\hline
\end{tabular}




\section{DATOS DE LA PUBLICACIÓN}

\begin{tabular}{|c|c|c|c|c|}
\hline Autor & Año & Nombre de la Investigación & $\begin{array}{c}\text { Revista donde su ubica la } \\
\text { publicación }\end{array}$ & Volumen y número \\
\hline \multicolumn{5}{|l|}{ Miranda, T., } \\
\hline Machado, H., & & & http://scielo.sld.cu/pdf/pyf/v42n1/2 & \\
\hline Lezcano, J., Suset, & & Aprendizajes en el proceso de gestión del & $\underline{078-8452-p y f-42-01-73 . p d f}$ & \\
\hline $\begin{array}{l}\text { A., Oropesa, K., } \\
\text { Tirado, F., Lamela, } \\
\text { L. y Montejo, I. }\end{array}$ & 2019 & desarrollo local en un municipio matancero & Pastos y Forrajes & $42(1)$ \\
\hline
\end{tabular}

\section{CONTENIDO DE LA PUBLICACIÓN}

\begin{tabular}{|c|c|c|c|c|c|}
\hline $\begin{array}{l}\text { Tipo y Diseño de } \\
\text { Investigación }\end{array}$ & $\begin{array}{l}\text { Población y } \\
\text { Muestra }\end{array}$ & Instrumentos & $\begin{array}{l}\text { Aspectos } \\
\text { éticos }\end{array}$ & Resultados & Conclusión \\
\hline $\begin{array}{l}\text { Básica- cualitativa- } \\
\text { fenomenológica }\end{array}$ & Ciudadanía local & Entrevistas & -Ninguno. & $\begin{array}{l}\text { La Plataforma Multiactoral de Gestión } \\
\text { ha brindado ventajas en la } \\
\text { conformación de un plan tramitado por } \\
\text { el Gobierno. El } 30 \% \text { de las personas } \\
\text { que fueron entrevistadas indica que el } \\
\text { trabajo efectuado ha facilitado la } \\
\text { modificación sobre la percepción y } \\
\text { actuación de diversas instituciones. }\end{array}$ & 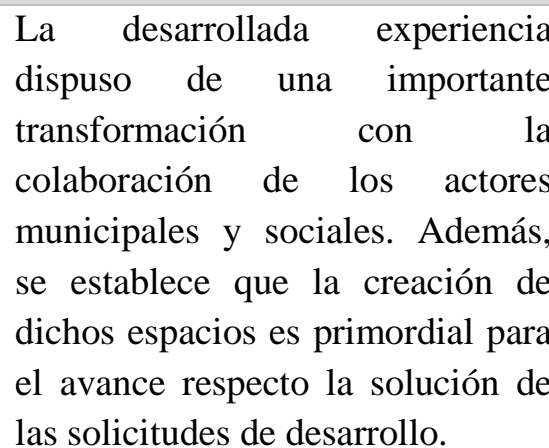 \\
\hline
\end{tabular}




\section{DATOS DE LA PUBLICACIÓN}

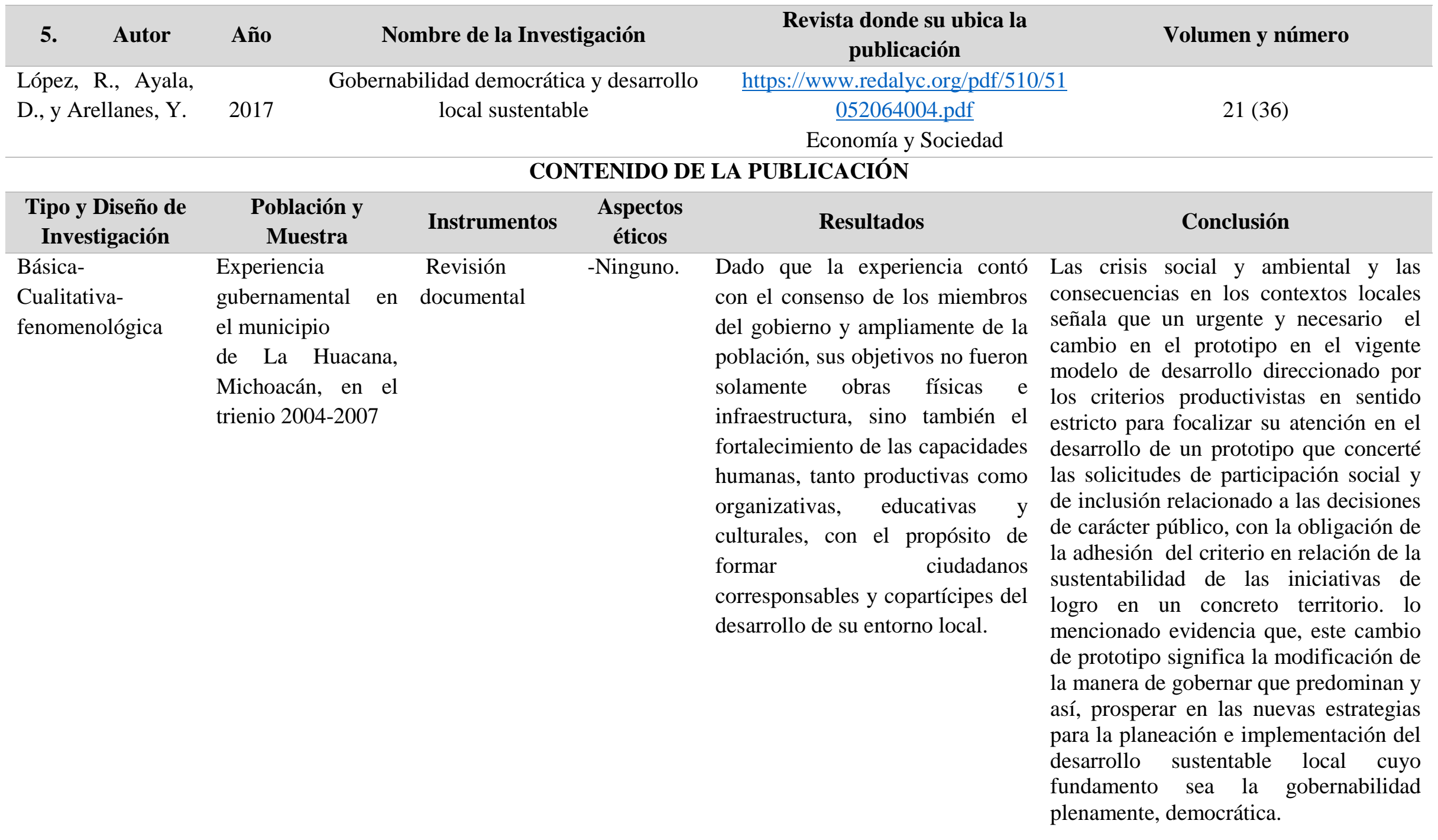




\section{DATOS DE LA PUBLICACIÓN}

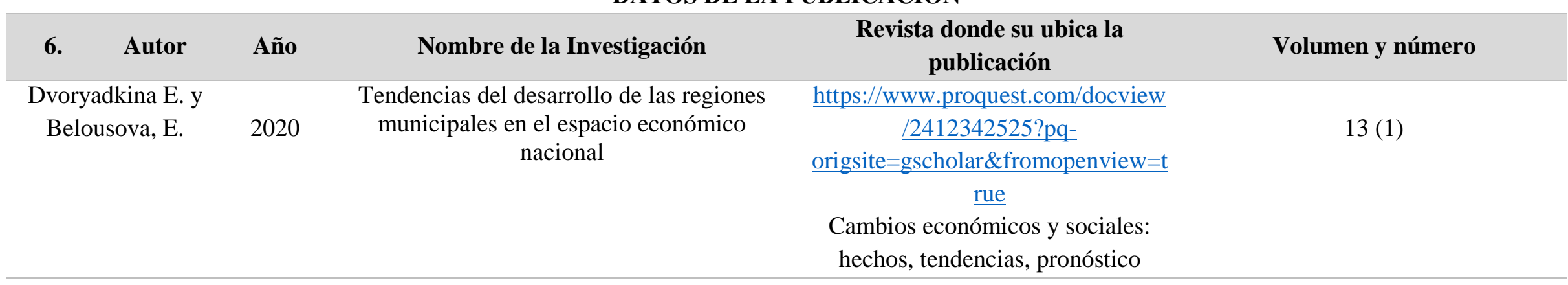

\begin{tabular}{|cccc|}
\hline Tipo y Diseño de & Población y & \multicolumn{2}{c|}{ CONTENIDO DE } \\
Investigación & Muestra & Instrumentos & $\begin{array}{c}\text { Aspectos } \\
\text { éticos }\end{array}$ \\
\hline Descriptiva & $\begin{array}{c}27 \text { distritos } \\
\text { municipales y 16 } \\
\text { distritos urbanos }\end{array}$ & $\begin{array}{c}\text { Análisis } \\
\text { Descriptivo }\end{array}$ & -Ninguno. \\
\hline
\end{tabular}

Resultados
Los índices de presencia, como la
relación entre la participación del
municipio en la región según el
indicador analizado y su colaboración
en la total población de la zona, se
calculan de acuerdo con los indicadores
del grupo de saturación con actividades
de agentes económicos.

Conclusión
A pesar de problemas similares
con el número de agentes
económicos, los distritos
municipales del Óblast de
Sverdlovsk tienen puntuaciones
más unificadas y altas de
actividades de producción
(productos agrícolas), el desarrollo
del marco espacial, en términos de
uso general y especializado de la
tierra, y la coherencia de espacio
económico según los indicadores
de conexión de autobús y
ferrocarril, y disponibilidad de
servicios postales y telefónicos
que los distritos municipales del
Óblast de Chelyabinsk.




\section{DATOS DE LA PUBLICACIÓN}

\begin{tabular}{|c|c|c|c|c|}
\hline Autor & Año & Nombre de la Investigación & $\begin{array}{c}\text { Revista donde su ubica la } \\
\text { publicación }\end{array}$ & Volumen y número \\
\hline Armas, G. & 2018 & $\begin{array}{l}\text { La gestión de servicios brindados por la } \\
\text { municipalidad y su efecto en el logro de las } \\
\text { comunidades. Caso municipalidades de la } \\
\text { provincia de Heredia, Costa Rica }\end{array}$ & $\begin{array}{l}\text { https://icap.academia.edu/RCAP } \\
\text { Revista Centroamericana de } \\
\text { Administración Publica }\end{array}$ & $1(74)$ \\
\hline
\end{tabular}

\begin{tabular}{|c|c|c|c|c|c|}
\hline \multicolumn{6}{|c|}{ CONTENIDO DE LA PUBLICACIÓN } \\
\hline $\begin{array}{l}\text { Tipo y Diseño de } \\
\text { Investigación }\end{array}$ & $\begin{array}{l}\text { Población y } \\
\text { Muestra }\end{array}$ & Instrumentos & $\begin{array}{l}\text { Aspectos } \\
\text { éticos }\end{array}$ & Resultados & Conclusión \\
\hline Básica-descriptiva & $\begin{array}{l}\text { Municipalidades de } \\
\text { la Provincia de } \\
\text { Heredia, Costa } \\
\text { Rica }\end{array}$ & $\begin{array}{l}\text { Revisión } \\
\text { documental }\end{array}$ & -Ninguno. & $\begin{array}{l}\text { La gestión de servicio social posibilita } \\
\text { la sensibilización de la población } \\
\text { mediante la construcción de procesos } \\
\text { caracterizados por ser participativos que } \\
\text { permiten la activa participación y la } \\
\text { negociación en el desarrollo de los } \\
\text { proyectos que son del interés de la } \\
\text { comunidad, y así fortalecer el trabajo } \\
\text { realizado en equipo entre la } \\
\text { municipalidad, el gobierno de la } \\
\text { localidad y las privaciones de la } \\
\text { localidad. }\end{array}$ & $\begin{array}{l}\text { La atención de obras sociales y } \\
\text { servicios }(69,12 \%) \text {, necesitan una } \\
\text { mayor atención en especial, en el } \\
\text { sector que no supera el } 33 \% \text { de la } \\
\text { calificación, lo cual obedecía a la } \\
\text { falta de antelación, carencia de } \\
\text { medios e inadecuado planeamiento } \\
\text { de las obras de beneficios de la } \\
\text { sociedad. }\end{array}$ \\
\hline
\end{tabular}


Tabla 2. Estudios revisados sobre desarrollo local

DATOS DE LA PUBLICACIÓN

\begin{tabular}{|c|c|c|c|c|}
\hline Autor & Año & Nombre de la Investigación & $\begin{array}{c}\text { Revista donde su ubica la } \\
\text { publicación }\end{array}$ & $\begin{array}{l}\text { Volumen y } \\
\text { número }\end{array}$ \\
\hline $\begin{array}{l}\text { Carrera, L. y } \\
\text { Galán, V. }\end{array}$ & 2020 & $\begin{array}{l}\text { Iniciativa Municipal de Desarrollo Local: una opción para la } \\
\text { producción cunícula }\end{array}$ & $\begin{array}{c}\text { https://anuarioeco.uo.edu.cu/index.p } \\
\text { hp/aeco/article/view/5173/4668 } \\
\text { Facultad de Ciencias Económicas y } \\
\text { Empresariales }\end{array}$ & $2(21)$ \\
\hline
\end{tabular}

\begin{tabular}{|c|c|c|c|c|c|}
\hline \multicolumn{6}{|c|}{ CONTENIDO DE LA PUBLICACIÓN } \\
\hline $\begin{array}{l}\text { Tipo y Diseño de } \\
\text { Investigación }\end{array}$ & $\begin{array}{c}\text { Población y } \\
\text { Muestra }\end{array}$ & Instrumentos & $\begin{array}{l}\text { Aspectos } \\
\text { éticos }\end{array}$ & Resultados & Conclusión \\
\hline Documental & $\begin{array}{l}38 \text { personas de la } \\
\text { comunidad de } \\
\text { Holguín, Cuba }\end{array}$ & $\begin{array}{l}\text { Entrevistas } \\
\text { semiestructu } \\
\text { radas }\end{array}$ & -Ninguno. & $\begin{array}{l}\text { Las tendencias en las migraciones } \\
\text { revelan la urgente necesidad de tomar } \\
\text { medidas encaminadas para la } \\
\text { retención poblacional con la } \\
\text { finalidad de brindar una garantía } \\
\text { respecto a la fuerza laboral necesaria } \\
\text { en el sector agropecuario para el } \\
\text { desarrollo agroalimentario del } \\
\text { municipio }\end{array}$ & $\begin{array}{l}\text { La producción de conejos } \\
\text { relacionada al proyecto } \\
\text { posibilitó la visualización la } \\
\text { viabilidad y la pertinencia } \\
\text { tomando como punto de inicio } \\
\text { del provecho de los potenciales } \\
\text { internos que otorgan los medios } \\
\text { tecnológicos, de la naturaleza y } \\
\text { el saber tradicional. }\end{array}$ \\
\hline
\end{tabular}




\section{DATOS DE LA PUBLICACIÓN}

\begin{tabular}{|c|c|c|c|c|}
\hline 2. Autor & A ño & Nombre de la Investigación & $\begin{array}{c}\text { Revista donde su ubica la } \\
\text { publicación }\end{array}$ & $\begin{array}{l}\text { Volumen y } \\
\text { número }\end{array}$ \\
\hline $\begin{array}{l}\text { De Armas, R. Tamayo } \\
\text { N. y Santos, M. }\end{array}$ & 2017 & $\begin{array}{l}\text { Población, territorio y gestión para un desarrollo local } \\
\text { sustentable }\end{array}$ & $\begin{array}{c}\frac{\text { http://scielo.sld.cu/scielo.php?pid=S }}{\underline{1817-}} \\
\frac{40782017000200013 \& \text { script=sci_art }}{\underline{\text { text\&tlng=en }}} \\
\text { Revista Novedades en Población }\end{array}$ & $13(26)$ \\
\hline
\end{tabular}

CONTENIDO DE LA PUBLICACIÓN

\begin{tabular}{|c|c|c|c|c|c|}
\hline $\begin{array}{l}\text { Tipo y Diseño de } \\
\text { Investigación }\end{array}$ & $\begin{array}{c}\text { Población y } \\
\text { Muestra }\end{array}$ & Instrumentos & $\begin{array}{l}\text { Aspectos } \\
\text { éticos }\end{array}$ & Resultados & Conclusión \\
\hline $\begin{array}{c}\text { Documental y diseño } \\
\text { descriptivo }\end{array}$ & $\begin{array}{l}15 \text { funcionarios } \\
\text { públicos }\end{array}$ & $\begin{array}{c}\text { Guía de } \\
\text { análisis } \\
\text { documental }\end{array}$ & -Ninguno. & $\begin{array}{l}\text { El desarrollo de las localidades es un complejo } \\
\text { fenómeno de la evolución del ser humano como } \\
\text { individuo social, es así que, los colectivos en los } \\
\text { que se integran y la sociedad local, además de } \\
\text { las estructuras sociales y económicas, así como } \\
\text { los sistemas relacionados al ambiente en el que } \\
\text { se desenvuelven exige de una perspectiva de un } \\
\text { sistema integral donde el aspecto decisivo es el } \\
\text { individuo y la dirección de las interacciones y } \\
\text { acciones que deben estar direccionadas al } \\
\text { desarrollo de los individuos sociales, al logro de } \\
\text { su bienestar, en base al crecimiento sostenible y } \\
\text { continuado del rendimiento de la producción } \\
\text { social, la eficacia de la gestión económica y el } \\
\text { desarrollo en la calidad de ambientes, vida y } \\
\text { trabajo que realizan los individuos y la gestión } \\
\text { local para fomentar su desarrollo. }\end{array}$ & $\begin{array}{l}\text { Se manifiesta que la } \\
\text { disposición de un } \\
\text { conjunto de indicadores } \\
\text { pertinentes y objetivos } \\
\text { que sean empleados para } \\
\text { la evaluación del nivel } \\
\text { alcanzado de desarrollo y } \\
\text { determinado momento, } \\
\text { siendo éste el paso inicial } \\
\text { para plantear las metas y } \\
\text { el modo que éstas pueden } \\
\text { ser logradas. De ahí que } \\
\text { sea fundamental, la } \\
\text { sistematicidad en el } \\
\text { proceso de control para el } \\
\text { establecimiento de } \\
\text { acciones que posibiliten } \\
\text { el desarrollo con eficacia } \\
\text { y eficiencia. }\end{array}$ \\
\hline
\end{tabular}




\section{DATOS DE LA PUBLICACIÓN}

$\begin{array}{cccc}\text { 3. Autor } & \text { Año } & \text { Nombre de la Investigación } & \begin{array}{c}\text { Revista donde su ubica la } \\ \text { publicación }\end{array} \\ \begin{array}{c}\text { Díaz, M. y } \\ \text { Fernández, A. }\end{array} & 2020 & \begin{array}{c}\text { Gestión de gobierno, educación superior, } \\ \text { ciencia, innovación y desarrollo local }\end{array} & \frac{\text { http://scielo.sld.cu/scielo.php?script }}{=\text { sci_arttext\&pid=S2306- }} \\ & & \frac{91552020000200005}{14} & \text { Retos de la Dirección }\end{array}$

CONTENIDO DE LA PUBLICACIÓN

\begin{tabular}{|c|c|c|c|c|c|}
\hline $\begin{array}{l}\text { Tipo y Diseño de } \\
\text { Investigación }\end{array}$ & $\begin{array}{c}\text { Población y } \\
\text { Muestra }\end{array}$ & Instrumentos & $\begin{array}{l}\text { Aspectos } \\
\text { éticos }\end{array}$ & Resultados & Conclusión \\
\hline $\begin{array}{l}\text { Cualitativa de tipo } \\
\text { exploratorio }\end{array}$ & $\begin{array}{c}\text { Ciudadanía de } \\
\text { Oaxaca, México }\end{array}$ & Entrevista & -Ninguno. & $\begin{array}{l}\text { No existe una positiva relación } \\
\text { entre los diferentes agentes } \\
\text { privados, públicos y locales, ni } \\
\text { los distintos grados de gobierno; } \\
\text { no interrelacionan el proceso de } \\
\text { logro local. Se indica la carencia } \\
\text { de una unidad de administración } \\
\text { que sus aptitudes sean el impulso } \\
\text { del logro de la comunidad. }\end{array}$ & $\begin{array}{l}\text { Para que la municipalidad lleve a } \\
\text { cabo el proceso de desarrollo de la } \\
\text { localidad es necesario el empleo de } \\
\text { mecanismos de actualización de la } \\
\text { gestión y, además, de una adecuada } \\
\text { organización administrativa con la } \\
\text { finalidad de disponer } \\
\text { pertinentemente de las capacidades } \\
\text { sobre la economía; que pueda } \\
\text { implementar, difundir y diseñar las } \\
\text { políticas de naturaleza pública sobre } \\
\text { el desarrollo, asimismo, se debe } \\
\text { considerar la relevancia de la } \\
\text { participación y movilización de los } \\
\text { involucrados locales. }\end{array}$ \\
\hline
\end{tabular}




\section{DATOS DE LA PUBLICACIÓN}

\begin{tabular}{|c|c|c|c|c|c|c|}
\hline 4. Autor & Año & \multicolumn{3}{|c|}{ Nombre de la Investigación } & $\begin{array}{c}\text { Revista donde su ubica la } \\
\text { publicación }\end{array}$ & Volumen y número \\
\hline \multirow[t]{2}{*}{ Cordero, $\mathrm{M}$. } & 2018 & \multicolumn{3}{|c|}{$\begin{array}{l}\text { El gobierno municipal. ¿Promotor del } \\
\text { desarrollo local? El caso del municipio } \\
\text { semiurbano de Cd. Ixtepec, Oaxaca }\end{array}$} & $\begin{array}{l}\text { http://www.scielo.org.mx/scielo.ph } \\
\text { p?script=sci_abstract\&pid=S2395- } \\
\text { 91692018000100006\&lng=es\&nrm }\end{array}$ & $28(52)$ \\
\hline & & & & & $\begin{array}{c}\text { Revista de alimentación } \\
\text { contemporánea y desarrollo } \\
\text { regional }\end{array}$ & \\
\hline \multicolumn{7}{|c|}{ CONTENIDO DE LA PUBLICACIÓN } \\
\hline $\begin{array}{l}\text { Tipo y Diseño de } \\
\text { Investigación }\end{array}$ & & $\begin{array}{l}\text { ión y } \\
\text { stra }\end{array}$ & Instrumentos & $\begin{array}{l}\text { Aspectos } \\
\text { éticos }\end{array}$ & Resultados & Conclusión \\
\hline $\begin{array}{l}\text { Exploratoria } \\
\text { cualitativa }\end{array}$ & $\begin{array}{r}\text { Datos } \\
\text { de los } \\
\text { prop } \\
\text { por e } \\
\text { L } \\
\text { Santic }\end{array}$ & $\begin{array}{l}\text { adísticos } \\
\text { imos } 10 \\
\text { os } \\
\text { onados } \\
\text { obierno } \\
1 \text { de } \\
\text { de Cuba }\end{array}$ & $\begin{array}{l}\text { Análisis } \\
\text { documental }\end{array}$ & -Ninguno. & $\begin{array}{l}\text { El estudio tuvo como finalidad la } \\
\text { realización de una conclusión a la } \\
\text { alcaldía de la municipalidad de Ciudad } \\
\text { de Ixtepec, Oaxaca, para estabecer si el } \\
\text { gobierno de la municipalidad de } \\
\text { Ciudad Ixtepec es quien promociona el } \\
\text { desarrollo local. Conforme a los } \\
\text { efectos no existe una positiva relación } \\
\text { entre los distintos personajes locales } \\
\text { privados y públicos ni los diferentes } \\
\text { rangos de gobierno; no interrelacionan } \\
\text { el procedimiento al logro de la } \\
\text { localidad. Se indica la carencia de una } \\
\text { unidad administrativa cuyas aptitudes } \\
\text { sean el impulso del logro de la } \\
\text { comunidad. }\end{array}$ & $\begin{array}{l}\text { Es el sector municipal, } \\
\text { exactamente, en donde las } \\
\text { personas logran identificar sus } \\
\text { carencias esenciales, ponen su } \\
\text { interés en los servicios } \\
\text { primordiales y llevan a cabo } \\
\text { acciones de tipo social, } \\
\text { personal, económico y } \\
\text { cultural. El interés público } \\
\text { tiende a manifestarse en los } \\
\text { valores y bienes que la } \\
\text { sociedad garantiza para } \\
\text { beneficiar a las personas } \\
\text { humanas: la paz el orden, la } \\
\text { seguridad, la justicia, el } \\
\text { bienestar. }\end{array}$ \\
\hline
\end{tabular}




\section{DATOS DE LA PUBLICACIÓN}

\begin{tabular}{|c|c|c|c|c|}
\hline Autor & Año & Nombre de la Investigación & $\begin{array}{c}\text { Revista donde su ubica la } \\
\text { publicación }\end{array}$ & Volumen y número \\
\hline \multirow{5}{*}{$\begin{array}{l}\text { Martínez, C., } \\
\text { Martínez, K., } \\
\text { Martínez L. y } \\
\text { Velasco, M. }\end{array}$} & 2020 & Relación entre la gestión pública y el & https://scielo.conicyt.cl/scielo.php? & \\
\hline & & desarrollo sustentable local de las ciudades & pid $=$ S0719- & $22(155-187)$ \\
\hline & & de Oaxaca, 2000-2017. & $17902020000200155 \&$ script=sci_a & \\
\hline & & & bstract & \\
\hline & & & $\begin{array}{l}\text { Revista iberoamericana de estudios } \\
\text { municipales }\end{array}$ & \\
\hline
\end{tabular}

\begin{tabular}{|c|c|c|c|c|c|}
\hline \multicolumn{6}{|c|}{ CONTENIDO DE LA PUBLICACIÓN } \\
\hline $\begin{array}{l}\text { Tipo y Diseño de } \\
\text { Investigación }\end{array}$ & $\begin{array}{l}\text { Población y } \\
\text { Muestra }\end{array}$ & Instrumentos & $\begin{array}{l}\text { Aspectos } \\
\text { éticos }\end{array}$ & Resultados & Conclusión \\
\hline $\begin{array}{l}\text { Tipo cuantitativo con } \\
\text { un nivel descriptivo y } \\
\text { correlacional. }\end{array}$ & $\begin{array}{l}\text { considera tres } \\
\text { pequeñas } \\
\text { ciudades y nueve } \\
\text { ciudades } \\
\text { medianas, } \\
\text { contempladas } \\
\text { como el } \\
\text { municipio en } \\
\text { conjunto y con } \\
\text { criterios para su } \\
\text { elección. }\end{array}$ & Observación & -Ninguno. & $\begin{array}{l}\text { Aunque el aspecto del desarrollo } \\
\text { local sostenido en las localidades de } \\
\text { Oaxaca es muy importante, y los } \\
\text { gobiernos locales que son los } \\
\text { generadores } \\
\text { de éste aun cuentan con deficiencias } \\
\text { derivadas de los aparatos } \\
\text { gubernamentales y formas de } \\
\text { gobierno de antaño, el resultado del } \\
\text { presente } \\
\text { artículo aportan datos para la } \\
\text { elección de decisiones, y la } \\
\text { elaboración } \\
\text { de estrategias en beneficio del } \\
\text { fortalecimiento de las instituciones } \\
\text { locales. }\end{array}$ & $\begin{array}{l}\text { Es evidente la diversidad de las } \\
\text { visiones en cuanto al tema } \\
\text { tratado, centrando la prioridad en } \\
\text { el fortalecimiento institucional y } \\
\text { financiero, así como la de } \\
\text { aprovechar todo el potencial } \\
\text { humano de cada ciudad para } \\
\text { implementar herramientas clave } \\
\text { para la generación de desarrollo } \\
\text { local. Finalmente, la clave del } \\
\text { éxito o fracaso de cualquier } \\
\text { gobierno local es la colaboración } \\
\text { con sus ciudadanos, teniendo una } \\
\text { nueva visión inclusiva y } \\
\text { proyectando su planificación } \\
\text { territorial sustentable. }\end{array}$ \\
\hline
\end{tabular}




\section{DATOS DE LA PUBLICACIÓN}

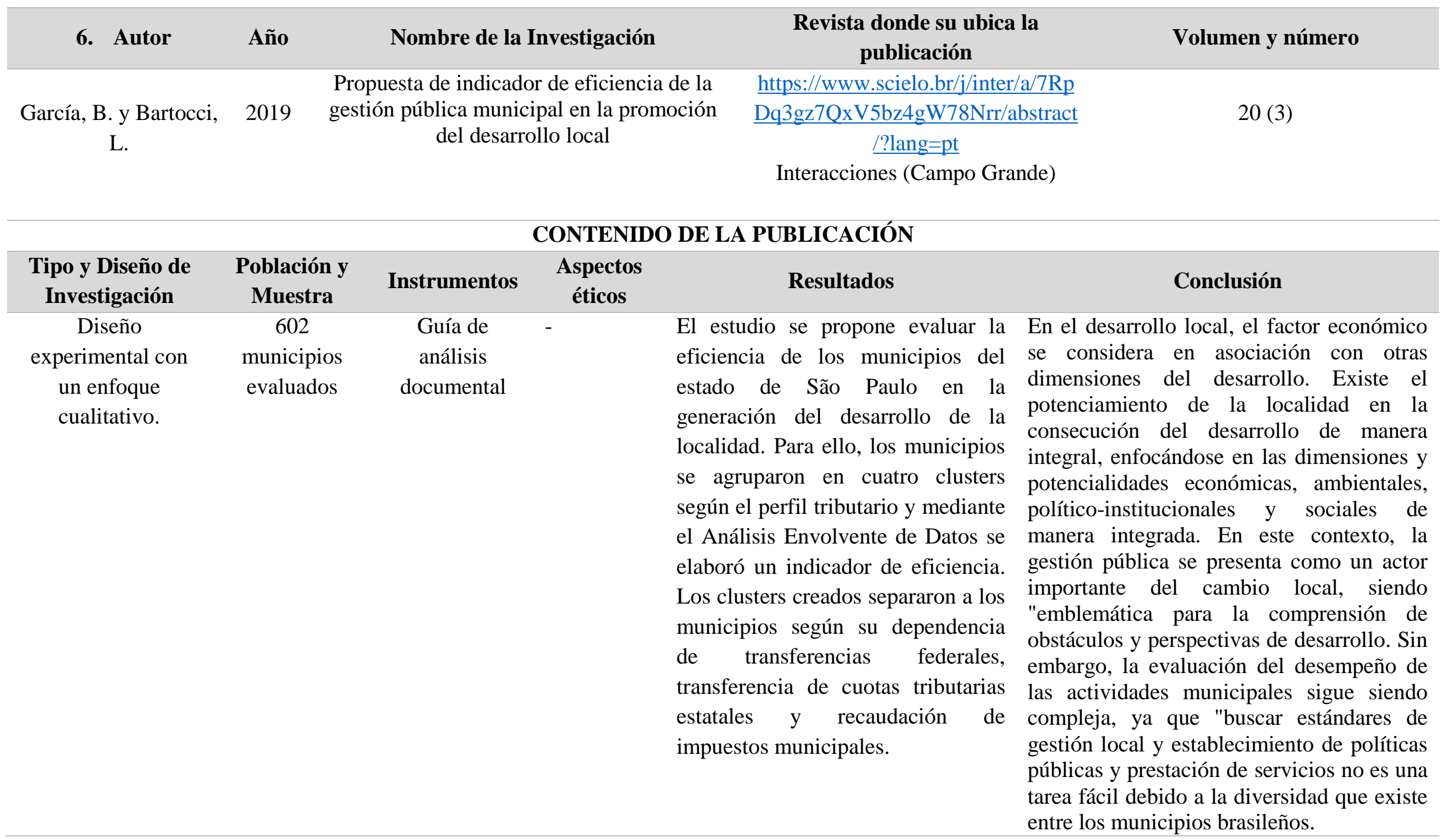




\title{
DATOS DE LA PUBLICACIÓN
}

\begin{tabular}{|c|c|c|c|c|}
\hline 7. Autor & Año & Nombre de la Investigación & $\begin{array}{c}\text { Revista donde su ubica la } \\
\text { publicación }\end{array}$ & Volumen y número \\
\hline Sánchez, F., & 2020 & Promoción de la financiación el sector & https://www.ciencialatina.org/index & 1(7) \\
\hline Moschini, M., & & público y desarrollo de la localidad & .php/cienciala/article/view/133/153 & \\
\hline $\begin{array}{c}\text { Guevara, J., } \\
\text { Camones, F., Loayza, } \\
\text { S. y Uribe, Y. }\end{array}$ & & municipal & $\begin{array}{l}\text { Revista Inclusiones, revista de } \\
\text { Humanidades y Ciencias Sociales }\end{array}$ & \\
\hline
\end{tabular}
S. y Uribe, Y.

\section{CONTENIDO DE LA PUBLICACIÓN}

\begin{tabular}{|cccc|}
\hline $\begin{array}{c}\text { Tipo y Diseño de } \\
\text { Investigación }\end{array}$ & $\begin{array}{c}\text { Población y } \\
\text { Muestra }\end{array}$ & Instrumentos & $\begin{array}{c}\text { Aspectos } \\
\text { éticos }\end{array}$ \\
\hline Básica-correlacional & $\begin{array}{c}34 \text { trabajadores } \\
\text { de la }\end{array}$ & Cuestionario & -Ninguno. \\
& municipalidad & & \\
\hline
\end{tabular}

\begin{abstract}
Resultados Spearman $\mathrm{r}=, 773$, por lo cual se concluyó que a mayor financiamiento en el sector publico provocará un mayor desarrollo en la economía del distrito mencionado para los pobladores de la comunidad de La Tinguiña.
\end{abstract}

Conclusión

Se estableció que el financiamiento en el Se estableció que el sector publico guarda relación directa financiamiento en el sector con el logro de la localidad, con un valor publico guarda relación rho Spearman $r=, 727$, concluyendo que directa con el desarrollo de la a mayor financiamiento en el sector economía, con un valor rho publico mayor desarrollo social para los Spearman ciudadanos de la comuna de $\mathrm{La} \quad \mathrm{r}=, 630$ concluyéndose que Tinguiña. Se estableció que la a mayor financiamiento en el financiamiento en el sector publico sector publico mayor guarda relación directa con el desarrollo desarrollo de la economía de la sociedad, con un valor de para los pobladores de la coeficiente de correlación de rho comunidad La Tinguiña. 
Tabla 3. Estudios revisados sobre gestión municipal en el desarrollo local

\section{DATOS DE LA PUBLICACIÓN}

\begin{tabular}{|c|c|c|c|c|}
\hline 1. Autor & Año & Nombre de la Investigación & $\begin{array}{c}\text { Revista donde su ubica la } \\
\text { publicación }\end{array}$ & Volumen y número \\
\hline $\begin{array}{l}\text { Coelho, R., Guth, F. y } \\
\text { Loureiro, M. }\end{array}$ & 2020 & $\begin{array}{l}\text { Capacidades gubernamentales } \\
\text { desarrollo municipal y humano } \\
\text { ubicación en Brasil }\end{array}$ & $\begin{array}{l}\frac{\text { https://opendocs.ids.ac.uk/opendocs }}{\text { /bitstream/handle/20.500.12413/15 }} \\
\frac{\text { 912/4524-Article\%20Text-17269- }}{\underline{1-10-}} \\
\frac{\text { 20201223.pdf? sequence=1\&isAllo }}{\underline{\text { wed=y }}}\end{array}$ & $71(4)$ \\
\hline
\end{tabular}

\begin{tabular}{|c|c|}
\hline $\begin{array}{l}\text { Tipo y Diseño de } \\
\text { Investigación }\end{array}$ & $\begin{array}{c}\text { Población y } \\
\text { Muestra }\end{array}$ \\
\hline Aplicada-correlacional & $\begin{array}{l}\text { Localidades } \\
\text { menos de } 50 \text { mil } \\
\text { habitantes, lo que } \\
\text { corresponde a } \\
\text { a } 4.916 \text { de los } \\
5.570 \text { municipios } \\
\text { brasileños }\end{array}$ \\
\hline
\end{tabular}

\section{CONTENIDO DE LA PUBLICACIÓN}

\section{Instrumentos Aspectos}

Regresiones -Ninguno.

logísticas

-Ninguno.

Los resultados sugieren que las actividades de planificación y la interacción con otros actores tienen una mayor asociación con el IDH-M que los recursos o las estructuras administrativas. La cantidad de consejos participativos, planes $\mathrm{y}$ consorcios tiene un efecto significativo y positivo. 


\section{DATOS DE LA PUBLICACIÓN}

\begin{tabular}{|c|c|c|c|c|}
\hline 2. Autor & Año & Nombre de la Investigación & $\begin{array}{c}\text { Revista donde su ubica la } \\
\text { publicación }\end{array}$ & Volumen y número \\
\hline Alonso, $\mathrm{M}$. & 2020 & $\begin{array}{l}\text { Repensar la acción pública local desde } \\
\text { nuevos modelos de gestión administrativa }\end{array}$ & $\begin{array}{c}\frac{\mathrm{https}: / / \text { revistasonline.inap.es/index. }}{\text { php/REALA/article/view/10808/11 }} \\
\text { Revista de } \underline{829} \\
\text { Estudios de la } \\
\text { Administración Local y } \\
\text { Autonómica }\end{array}$ & $1(14)$ \\
\hline
\end{tabular}

\begin{tabular}{|c|c|c|c|}
\hline $\begin{array}{l}\text { Tipo y Diseño de } \\
\text { Investigación }\end{array}$ & $\begin{array}{l}\text { Población y } \\
\text { Muestra }\end{array}$ & Instrumentos & $\begin{array}{l}\text { Aspectos } \\
\text { éticos }\end{array}$ \\
\hline $\begin{array}{l}\text { Básica-cualitativa- } \\
\text { fenomenológica }\end{array}$ & $\begin{array}{l}24 \text { artículos sobre } \\
\text { acción pública local } \\
\text { de España }\end{array}$ & $\begin{array}{l}\text { Revisión } \\
\text { documental }\end{array}$ & -Ninguno. \\
\hline
\end{tabular}

A pesar del aprendizaje obtenido por las instituciones locales por medio de esta vía, es fundamental una regulación que permita la sustantividad en el régimen local a estas colaborativas fórmulas; ello repercute de nuevo en la capacidad institucional local para enfrentar los retos que se asocian a las políticas urbanas, para establecerse en su condición de autoridad de la comunidad urbana, que tendría que ser reforzada en su normativa.

\section{Conclusión}

Desde el fortalecimiento jurídicoinstitucional de todas sus capacidades, políticas institucionales, los municipios podrían gestionar una parte sustancial de los asuntos públicos, aquellos que afecten a la comunidad local. En particular, podrían en mejores condiciones ser «autoridades de las comunidades urbanas" referidas a la gestión de las políticas urbanas nuevas, en el contexto que ha sido expuesto en este trabajo. Las circunstancias sobre la sostenibilidad producen una afectación en la localidad, y a su población sumida en la colectividad. Tratándose únicamente sobre un aspecto de supervivencia. 


\section{DATOS DE LA PUBLICACIÓN}

\begin{tabular}{cccc}
\hline $\begin{array}{c}\text { 3. Autor } \\
\text { Ladillinsky, A. }\end{array}$ & Año & Nombre de la Investigación & $\begin{array}{c}\text { Revista donde su ubica la } \\
\text { publicación }\end{array}$ \\
\hline & 2020 & $\begin{array}{l}\text { Resiliencia urbana y desarrollo local: } \\
\text { planificación de la gestión municipal }\end{array}$ & $\frac{\text { http://revistas.unla.edu.ar/perspecti }}{\frac{\text { vas/article/view/3326/1690 }}{\text { Revista Perspectivas de Políticas }}}$ \\
Públicas & $(10) 9)$
\end{tabular}

\begin{tabular}{|c|c|c|c|c|}
\hline & & \multicolumn{3}{|c|}{ CONTENIDO DE LA PUBLICACIÓN } \\
\hline $\begin{array}{l}\text { Tipo y Diseño de } \\
\text { Investigación }\end{array}$ & $\begin{array}{c}\text { Población y } \\
\text { Muestra }\end{array}$ & Instrumentos & $\begin{array}{l}\text { Aspectos } \\
\text { éticos }\end{array}$ & Resultados \\
\hline Básica descriptiva & $\begin{array}{c}\text { Artículos de } \\
\text { investigación } \\
\text { nacionales como } \\
\text { e internacionales }\end{array}$ & $\begin{array}{c}\text { Análisis } \\
\text { documental }\end{array}$ & -Ninguno. & $\begin{array}{l}\text { El desmembramiento y/o } \\
\text { transferencia de funciones y } \\
\text { competencias de áreas } \\
\text { completas de la administración } \\
\text { pública nacional, la expulsión de } \\
\text { recursos humanos -en muchos } \\
\text { casos los más preparados- y la } \\
\text { desmotivación de los que aún } \\
\text { permanecen tras años de destrato, } \\
\text { el desfinanciamiento, falta de } \\
\text { inversión y pérdida de ingresos } \\
\text { de las empresas estatales, el } \\
\text { abandono o desmantelamiento } \\
\text { de sus bienes, constituyen } \\
\text { algunos de los resultados de la } \\
\text { modernización encarada por el } \\
\text { gobierno de la alianza } \\
\text { Cambiemos. }\end{array}$ \\
\hline
\end{tabular}

Ciencia Latina Revista Científica Multidisciplinar, Ciudad de México, México. 


\section{DATOS DE LA PUBLICACIÓN}

\begin{tabular}{cccccc}
\multicolumn{1}{c}{ 4. Autor } & Año & Nombre de la Investigación & $\begin{array}{c}\text { Revista donde su ubica la } \\
\text { publicación }\end{array}$ & Volumen y número \\
$\begin{array}{c}\text { Gaviria, R. y Delgado, } \\
\text { M. }\end{array}$ & 2020 & $\begin{array}{c}\text { Mejora de los servicios públicos en el } \\
\text { fortalecimiento de la gestión municipal }\end{array}$ & $\begin{array}{c}\text { https://ciencialatina.org/index.php/c } \\
\text { ienciala/article/view/151/182 }\end{array}$ & \\
$\begin{array}{c}\text { Ciencia Latina Revista Científica } \\
\text { Multidisciplinar }\end{array}$ & $4(2)$ & \\
\hline
\end{tabular}

\section{CONTENIDO DE LA PUBLICACIÓN}

\begin{tabular}{|c|c|c|c|c|c|}
\hline $\begin{array}{l}\text { Tipo y Diseño de } \\
\text { Investigación }\end{array}$ & $\begin{array}{l}\text { Población y } \\
\text { Muestra }\end{array}$ & Instrumentos & $\begin{array}{l}\text { Aspectos } \\
\text { éticos }\end{array}$ & Resultados & Conclusión \\
\hline $\begin{array}{l}\text { Cualitativo diseño de } \\
\text { estudio }\end{array}$ & $\begin{array}{l}\text { artículos de } \\
\text { investigaciones } \\
\text { tanto nacionales } \\
\text { como } \\
\text { internacionales }\end{array}$ & $\begin{array}{l}11 \text { artículos } \\
\text { indexados }\end{array}$ & -Ninguno. & $\begin{array}{l}\text { La asistencia de las } \\
\text { prestaciones } \\
\text { enfocadas en la ciudadanía } \\
\text { es tarea del gobierno } \\
\text { nacional y local para brindar } \\
\text { una solución efectiva a las } \\
\text { necesidades de los } \\
\text { ciudadanos, garantizando la } \\
\text { accesibilidad de los mismos, } \\
\text { gestionando estándares de } \\
\text { calidad y asegurando el } \\
\text { apoyo político para el } \\
\text { desarrollo social y humano. }\end{array}$ & $\begin{array}{l}\text { Ante los diferentes cambios que se generan } \\
\text { en la administración pública, los servicios } \\
\text { públicos, debe estar siempre orientados al } \\
\text { ciudadano, } \\
\text { Cuya finalidad debe ser la justificación y el } \\
\text { logro de las consecuencias referidas a la } \\
\text { calidad, teniendo en cuenta los tipos y } \\
\text { características del poblador y de las } \\
\text { condiciones geográficas de la misma }\end{array}$ \\
\hline
\end{tabular}




\section{DATOS DE LA PUBLICACIÓN}

\begin{tabular}{cccc|c}
\hline \multicolumn{1}{c}{ 5. Autor } & Año & Nombre de la Investigación & $\begin{array}{c}\text { Revista donde su ubica la } \\
\text { publicación }\end{array}$ & Volumen y número \\
$\begin{array}{c}\text { Vargas, M., Fernández, } \\
\text { L., Quiroz, J. y Cacho, } \\
\text { A. } 2020\end{array}$ & $\begin{array}{c}\text { Gestión de la municipalidad y la reacción } \\
\text { frente al efecto del COVID 19- } \\
\text { municipalidades de la zona alto andina, } \\
\text { departamento de Lambayeque }\end{array}$ & $\begin{array}{c}\frac{\text { http://revistas.unj.edu.pe/index.php/ }}{\text { pakamuros/article/view/153/133 }} \\
\text { Revista Científica Pakamuros }\end{array}$ & $8(4)$ \\
\hline
\end{tabular}

\section{CONTENIDO DE LA PUBLICACIÓN}

\begin{tabular}{|c|c|c|c|c|c|}
\hline $\begin{array}{l}\text { Tipo y Diseño de } \\
\text { Investigación }\end{array}$ & $\begin{array}{l}\text { Población y } \\
\text { Muestra }\end{array}$ & Instrumentos & $\begin{array}{l}\text { Aspectos } \\
\text { éticos }\end{array}$ & Resultados & Conclusión \\
\hline $\begin{array}{l}\text { Enfoque socio crítico } \\
\text { de investigación } \\
\text { descriptiva, }\end{array}$ & $\begin{array}{l}\text { Informes de la } \\
\text { Defensoría del } \\
\text { Pueblo, } \\
\text { REDATAM- } \\
2017 \text { del Instituto } \\
\text { de Estadística e } \\
\text { Informática, la } \\
\text { Encuesta } \\
\text { Demográfica y de } \\
\text { Salud Familiar y } \\
\text { artículos de } \\
\text { periódicos }\end{array}$ & 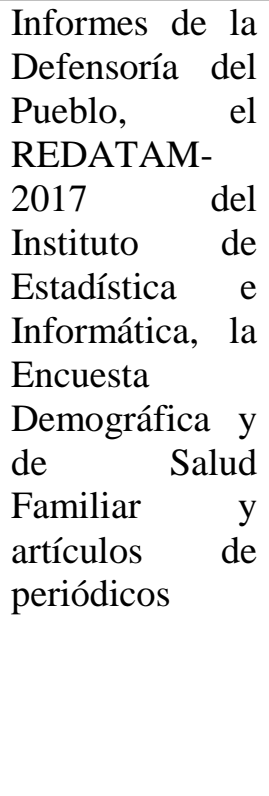 & -Ninguno. & $\begin{array}{l}\text { La incapacidad de respuesta } \\
\text { por los municipios ha } \\
\text { violentado sus fundamentales } \\
\text { derechos y ha provocado un } \\
\text { riesgo considerable en sus } \\
\text { condiciones de bienestar y salud } \\
\text { frente al COVID }-19 \text {. La } \\
\text { ejecución presupuestal fue del } 6.7 \\
\text { y no mayor al } 39 \% \text {, reflejando el } \\
\text { bajo desempeño de la gestión } \\
\text { municipal, como consecuencia de } \\
\text { la incapacidad de los gastos, la } \\
\text { articulación deficiente de los } \\
\text { planes y políticas vinculadas en el } \\
\text { prepuesto a causa de los cuellos } \\
\text { de botella que existen en la } \\
\text { operatividad de la función } \\
\text { pública. }\end{array}$ & $\begin{array}{l}\text { El territorio alto andino, es una } \\
\text { marcada zona por las desigualdades, } \\
\text { las que involucran factores políticos, } \\
\text { sociales y económicos y en aras de } \\
\text { dar mejoría al contexto en el que se } \\
\text { enfrenta en tiempos de pandemia y } \\
\text { al mismo tiempo seguir con la } \\
\text { modernidad del estado peruano, es } \\
\text { indispensable conocer y caracterizar } \\
\text { la realidad territorial para la } \\
\text { implementación de las políticas } \\
\text { públicas con enfoque intercultural y } \\
\text { poder instrumentalizar en los planes la } \\
\text { labor que se debe desarrollar. }\end{array}$ \\
\hline
\end{tabular}




\section{DATOS DE LA PUBLICACIÓN}

\begin{tabular}{|c|c|c|c|c|}
\hline \\
\hline 6. Autor & Año & mbre de la Investigación & $\begin{array}{c}\text { Revista donde su ubica la } \\
\text { publicación }\end{array}$ & Volumen y número \\
\hline $\begin{array}{l}\text { Tipo y Diseño de } \\
\text { Investigación }\end{array}$ & $\begin{array}{l}\text { Población y } \\
\text { Muestra }\end{array}$ & $\begin{array}{lc}\text { Instrumentos } & \begin{array}{c}\text { Aspectos } \\
\text { éticos }\end{array}\end{array}$ & Resultados & Conclusión \\
\hline $\begin{array}{l}\text { Cuantitativo con un } \\
\text { nivel descriptivo } \\
\text { correlacional }\end{array}$ & $\begin{array}{l}\text { Pobladores entre } \\
18 \text { y } 64 \text { años de } \\
\text { edad. Mediante } \\
\text { un muestreo del } \\
\text { tipo } \\
\text { probabilístico se } \\
\text { seleccionó una } \\
\text { muestra de } 132 \\
\text { personas }\end{array}$ & $\begin{array}{l}\text { Test Exacto de -Ninguno. } \\
\text { Fisher }\end{array}$ & $\begin{array}{l}\text { Indicador } \quad \text { general } \\
\text { percepción negativa de } 30,99 \%, \\
\text { así como la existencia de } \\
\text { dependencia entre el nivel de } \\
\text { confianza y los niveles de } \\
\text { percepción respecto a la } \\
\text { asistencia de prestaciones para } \\
\text { la gestión municipal actual, } \\
\text { concluyendo así que el nivel } \\
\text { bajo de confianza que se tiene en } \\
\text { la gestión de la municipalidad } \\
\text { actual requiere de los bajos } \\
\text { grados de apreciación referidos a } \\
\text { la asistencia de servicios }\end{array}$ & $\begin{array}{l}\text { Fue evidente la existencia de } \\
\text { dependencia en los ocho indicadores } \\
\text { de la variable "nivel de percepción } \\
\text { con respecto a la prestación de } \\
\text { servicios" y la variable "nivel de } \\
\text { confianza en la actual gestión } \\
\text { municipal", dado que estos } \\
\text { indicadores fueron los que indicaron } \\
\text { un mayor grado de percepción } \\
\text { negativa brindada por la población } \\
\text { chachapoyana. }\end{array}$ \\
\hline
\end{tabular}




\section{DATOS DE LA PUBLICACIÓN}

\begin{tabular}{|c|c|c|c|c|}
\hline 7. Autor & \multicolumn{2}{|c|}{ Nombre de la Investigación } & $\begin{array}{c}\text { Revista donde su ubica la } \\
\text { publicación }\end{array}$ & Volumen y número \\
\hline $\begin{array}{l}\text { Gorina, A. Martín, } \\
\text { M. Alonso, I. } \\
\text { Gorina, N. }\end{array}$ & $\begin{array}{r}\text { Desarrollo } \\
\text { desde } \\
\text { diagnós }\end{array}$ & $\begin{array}{l}\text { local; desarrollo regional; agenda } \\
\text { lo local; gobierno; municipal } \\
\text { tico municipal; Ciudad Ixtepec. }\end{array}$ & $\begin{array}{c}\underline{\underline{\text { http://www.revista- }}} \\
\underline{\text { batey.com/index.php/batey/article/v }} \\
\underline{\text { iew/226/152 }} \\
\text { Batey. Revista Cubana De } \\
\text { Antropología Sociocultural }\end{array}$ & $11(13)$ \\
\hline \multicolumn{5}{|c|}{ CONTENIDO DE LA PUBLICACIÓN } \\
\hline $\begin{array}{l}\text { Tipo y Diseño de } \\
\text { Investigación }\end{array}$ & $\begin{array}{c}\text { Población y } \\
\text { Muestra }\end{array}$ & $\begin{array}{l}\text { Aspectos } \\
\text { éticos }\end{array}$ & Resultados & Conclusión \\
\hline $\begin{array}{l}\text { Exploratoria } \\
\text { cualitativa }\end{array}$ & $\begin{array}{l}\text { Datos estadísticos } \\
\text { de los últimos } 10 \\
\text { años } \\
\text { proporcionados } \\
\text { por el Gobierno } \\
\text { Local de } \\
\text { Santiago de Cuba }\end{array}$ & $\begin{array}{l}\text { Análisis } \\
\text { documental }\end{array}$ & $\begin{array}{l}\text { Los recursos más relevantes del contexto } \\
\text { local son las personas, ya que ellas } \\
\text { constituyen el motor que impulsa el } \\
\text { desarrollo interno, y a raíz de ello, éste } \\
\text { debe proyectarse en concordancia con su } \\
\text { cultura, temores, valores, ideas y } \\
\text { relaciones sociales. Es necesario, además, } \\
\text { para su gestión, se ponga en práctica una } \\
\text { gestión democrática y participativa donde } \\
\text { estén involucradas las personas como } \\
\text { parte de los procesos locales que } \\
\text { configuran y reflejan para dar significado } \\
\text { al contexto de la localidad, eligiendo el } \\
\text { tipo de desarrollo que es necesario en su } \\
\text { localidad para conseguir condiciones de } \\
\text { vida superiores, no solo en el logro a nivel } \\
\text { personal sino en logro del bienestar } \\
\text { comunitario. }\end{array}$ & $\begin{array}{l}\text { Es evidente la necesidad de la } \\
\text { aplicación de esta perspectiva de } \\
\text { descentralización centralizada, } \\
\text { mediante la creación de } \\
\text { condiciones subjetivas y } \\
\text { objetivas para la disminución de } \\
\text { existentes brechas entre la } \\
\text { concepción metodológica- } \\
\text { teórica y su realización práctica. }\end{array}$ \\
\hline
\end{tabular}




\section{DISCUSIÓN}

Como consecuencia de un proceso acelerado de mercantilización en la prestación de los básicos servicios en la cotidianidad, lo resaltante, son las ganancias que producen; siendo que, la municipalización en el sector educación, salud, agua y transporte, son percibidos como sectores donde puede surgir las oportunidades para la recuperación del real rol del Estado constitucional. Es así que, se considera que el diseño institucional de las municipalidades exige una descentralización sociológica, administrativa, jurídica y política, debido a que se determina su misión articuladora en la división territorial de las tareas de naturaleza administrativa dirigidas a la asistencia de prestaciones de servicios básicos públicos para la satisfacción de las carencias de la localidad y fomentar el desarrollo de la misma y las personas que la conforman.

Ante los diferentes cambios que se generan en la administración pública, Gaviria y Delgado (2020), señalan que los servicios públicos, deben direccionarse a los ciudadanos, cuya finalidad consiste en satisfacer y cumplir con los parámetros de calidad, teniendo en cuenta las características específicas de los pobladores y sus contextos geográficos. El principal objetivo de las municipalidades o gobiernos locales es la creación de las aptitudes que faciliten la asistencia de las carencias de los ciudadanos y asegurar no solo el bienestar social, sino el cultural y el económico de cada comunidad. Esta finalidad se alcanza a través de una serie de implementaciones de proyectos referentes a la inversión y políticas públicas que son consideradas prioritarias para beneficio de la ciudadanía.

Consecuentemente, basado a los hallazgos encontrados en el presente estudio queda demostrado en relación a la gestión municipal según Díaz y Fernández, (2020) que, para que la municipalidad lleve a cabo el proceso de desarrollo de la localidad es necesario el empleo de mecanismos de actualización de la gestión y, además, de una adecuada estructura de la administración con la finalidad de disponer pertinentemente de las capacidades de la economía; que pueda implementar, difundir y diseñar las políticas públicas sobre el logro, asimismo, se debe considerar la relevancia de la participación y movilización de los involucrados locales.

Asimismo, Ladillinsky (2020), agrega que, desde un enfoque instrumental, el trabajo centra su mirada en decisores y gestores de políticas públicas, con eje no excluyente en la etapa preparatoria del arribo a la gestión. Una propuesta de abordaje que pueda ser de utilidad para decisores y gestores, y para aquellos interesados en la planificación de una gestión pública que implemente políticas en las que la eficiencia y la efectividad dejen de 
ser antagónicas de la equidad. Políticas públicas que reconozcan como norte la promoción del desarrollo y el crecimiento económico, la guerra contra la hambruna y los altos índices de pobreza en la totalidad de dimensiones y maneras, y el abordaje de necesidades sociales insatisfechas para el desarrollo de comunidades más resilientes.

Por lo que vale destacar que, las iniciativas tomadas por las municipalidades se direccionan para el logro del desarrollo de la comunidad así como por el progreso económico, como un aspecto que dinamiza todas las dimensiones relacionadas al desarrollo de la comunidad, que pretende afianzar un equilibrado crecimiento, además de lo relacionado con el comercio, la producción y servicios con el propósito de dar satisfacción a los requerimientos e incrementar la condición de vida de los pobladores por medio de una dinámica economía local. Empero, no todas las municipalidades tienen ventajas semejantes competitivas y comparativas, así como las políticas teniendo en cuenta la territorialidad son diversas, conforme la realidad problemática de cada uno de ellas. Asimismo, la competitividad internacional y nacional excluye ciertas zonas de la red económica.

A razón de ello, Coelho, Guth y Loureiro (2020), señalan que la intervención de los personajes involucrados en la sociedad civil en la gestión municipal, las alianzas intra e intermunicipales y el acto de planificar están fuertemente asociados con índices de IDH-M altos. Mientras que, Gorina, Martín, Alonso y Gorina (2018), expresan que es evidente la necesidad de la aplicación de esta perspectiva de descentralización centralizada, mediante la creación de condiciones subjetivas y objetivas para la disminución de existentes brechas entre la concepción metodológica-teórica y su realización práctica. Por su parte, Quispe, Ayaviri y Maldonado (2018), coinciden y manifiestan que se evidencia un significativo nivel de colaboración por parte de los gestores locales involucrados en los proyectos productivos y sociales, así mismo, respecto a la colaboración de los pobladores, direcciona a identificar escenarios innovadores y ámbitos para el logro del desarrollo local; debido a que los agentes y actores de desarrollo son los que resuelven los procesos de desarrollo, los modos de producción y el bienestar comunitario del contexto rural.

Por lo expuesto, resulta destacar que los municipios asumen las responsabilidades sociales que exige el actual nivel de descentralización, pero sus gerentes aún no están completamente preparados, de ahí que la finalidad de esta investigación es brindar un compuesto de indicadores orientados a la calidad de la gestión y promuevan el desarrollo sostenible de la localidad, y a su vez, lograr la satisfacción por parte de los pobladores de la comunidades, con la finalidad de mejorar y evaluar la gestión local respecto a las 
necesidades distintas de los diversos territorios, características de tales y las capacidades de la población. Por lo tanto, es necesario mejorar el desarrollo local de manera inclusiva y sostenible para combatir la corrupción y otros delitos mayores, pues con la colaboración de la comunidad se monitoreará el uso correcto de los recursos públicos.

En relación a ello, manifiesta que la disposición de un conjunto de indicadores pertinentes y objetivos que sean empleados para la evaluación del nivel alcanzado de desarrollo y determinado momento, siendo éste el paso inicial para plantear las metas y el modo que éstas pueden ser logradas. De ahí que sea fundamental, la sistematicidad en el proceso de control para el establecimiento de acciones que posibiliten el desarrollo con eficacia y eficiencia.

Por su parte, López., Ayala y Arellanes (2017), señala que un urgente y necesario el cambio en el prototipo en el vigente modelo de desarrollo direccionado por los criterios productivistas en sentido estricto para focalizar su atención en el desarrollo de un prototipo que concerté las solicitudes de participación social y de inclusión relacionado a las decisiones de carácter público, con la obligación de la integración del criterio en relación de la sustentabilidad de las iniciativas de logro en un concreto territorio.

Finalmente, después de analizados los resultados de los artículos seleccionados, podemos sintetizar que una buena gestión municipal para el desarrollo local significa el reforzamiento de cuatro variables: gestión operativa, gestión de las instituciones, sobre el financiamiento y presupuestaria, que se relacionan con las dimensiones social, económica, ambiental y política. Además, la gestión exitosa de los gobiernos locales depende en gran medida del liderazgo de los funcionarios. Es decir, las condiciones, el cual son cualidades o atributos que complementan el aspecto técnico de la gestión municipal. En referencia a los aspectos ya discutidos, se señala que éstos están integrados, transformados y se evidencian en los servicios públicos prestados, esta es la capacidad convencional asociada a los municipios, estos servicios se dirigen principalmente a la población local cumpliendo roles de beneficiarios y también de fiscalizadores.

De esta manera, vale destacar el contexto que señala que los gobiernos municipales han entrado en una etapa nueva, que se caracteriza por ser responsables de personas con mayores niveles de educación, niveles mayores de demanda, expectativas mayores respecto al funcionamiento del municipio y menor confianza, esto puede ser impulsado por la situación política nacional, el cual está contaminada a través de una corrupción continua que puede tener un impacto a nivel local. Esto nos posibilita el entendimiento respecto al 
nivel de confianza de los pobladores respecto a la gestión local, la cual depende significativamente de las percepciones referidos a la prestación de la asistencia ofrecida por las municipalidades.

\section{CONCLUSIONES Y RECOMENDACIONES:}

Luego del análisis de los resultados y las conclusiones obtenidas de acuerdo a los objetivos de la revisión sistemática, se ha determinado que las investigaciones que más predominan han sido las de tipo básico, enfoque cualitativo y diseño descriptivo. Por otra parte, estos se encuentran organizados desde diferentes realidades gubernamentales, entre ellas con mayor relevancia del contexto Latinoamericano. Vale precisar que los estudios guardan correlación con la perspectiva de las necesidades involucradas en el concepto de la gestión municipal.

En cuanto a la variable en estudio, se puede sinterizar que la gestión pública se presenta como un actor o elemento importante del cambio local, siendo emblemática para la comprensión de obstáculos y perspectivas de desarrollo. El principal objetivo de los gobiernos municipalidades o locales es la creación de las aptitudes que faciliten la satisfacción de las prioridades de sus pobladores y asegurar así el bienestar social, económico cultural de las distintas comunidades, No obstante, la evaluación del desempeño de las actividades municipales sigue siendo compleja, puesto que buscar estándares de gestión local y establecimiento de políticas públicas y prestación de servicios, en la realidad, no es una tarea fácil.

En cuanto a las dimensiones asociadas a la variable, existe el desarrollo de las comunidades en la necesidad de empoderamiento como parte del desarrollo de manera integral, enfocándose en las dimensiones y potencialidades económicas, ambientales, político-institucionales y sociales de manera integrada. La gestión municipal, de forma progresiva, ha asumido una función relacionada a la promoción de empoderamiento local, incorporando cambios en su dimensión estructural, el cual debe significar la garantía del establecimiento de las tareas pertinentes, para la concreción de visión, metas, objetivos y misión establecidas, en base a la consecución de eficiencia, cuyo logro será posible con la coordinación y ordenamiento racional de los recursos en tu totalidad con lo que disponga dicha municipalidad, y a su vez lograr el propósito de poder identificar la dimensión funcional y demás estructuras endógenas, ordenándolas y agrupándolas para la asignación, transferencia o delegación de responsabilidades y específicas funciones. 
Respecto a las dimensiones de planificación y evaluación, estos resultan esenciales para la valoración y seguimiento de los resultados de políticas o estrategias, relacionadas a su capacidad de provocar la generación de bienestar, en determinado momento debe medirse en términos referidos a los indicativos de circunstancias de vida de las localidades. De ahí que, el estudio realizado a los indicativos de impacto sobre las políticas surge como un dispositivo de control para garantizar la eficiencia eficacia en la disposición de determinaciones, además de la delineación de políticas adecuadas donde la dimensión tecnológica se complemente y contribuya al desarrollo gestionado por la municipalidad. Finalmente, el estudio contribuye proponiendo un indicador de eficiencia pública utilizando múltiples dimensiones del desarrollo local. Además de contribuir de manera práctica con los gestores municipales que puedan identificar las mejores prácticas de los municipios y reflexionar sobre cómo la gestión puede contribuir de manera eficiente al desarrollo de sus regiones.

Por todo lo mencionado, se expresan las recomendaciones siguientes para los gobiernos Municipales, el cual se hace necesario utilizar las diferentes propuestas de gestión municipal que están orientadas a superar el deficiente desarrollo institucional en la municipalidad.

- Se recomienda a la gestión del gobierno municipal de la Provincia Mariscal Cáceres, la generación de oportunidades, el desarrollo de los pobladores, poniendo énfasis en el trabajo realizado en comunidad y, favorecer la creación de cadenas productivas, aspectos que facilitarán de manera favorable la gestión realizada por el gobierno local $\mathrm{y}$, consecuentemente, las circunstancias en que viven los pobladores de la comunidad.

- Se recomienda a la gerencia municipal de la provincia Mariscal Cáceres, diseñar y aplicar los instrumentos pertinentes para el control de la gestión y así evaluar los objetivos establecidos en el plan estratégico, y así llevar a cabo el seguimiento de tales objetivos de manera adecuada y oportuna, con el fin de realizar la identificación de las debilidades y, posteriormente, la realización de los pertinentes ajustes direccionados al cumplimiento de la totalidad de los objetivos establecidos.

- Se recomienda a la gerencia municipal de la provincia Mariscal Cáceres, y sub gerentes de las diversas áreas, la difusión de las políticas y fines entre todos los empleados involucrados y llevar a cabo el permanente seguimiento de la utilidad de sus proyectos de trabajo y consecuentemente, lograr el mejoramiento de la gestión empleada en los gobiernos de las localidades. 
- Se recomienda a los funcionarios involucrados en la Municipalidad de la provincia Mariscal Cáceres, efectuar acciones encaminadas al alza respecto a los niveles de eficacia y eficiencia, a fin de lograr un mejor servicio a los ciudadanos a través del uso de las TIC.

\section{REFERENCIAS}

Álvarez, N. y Delgado, J. (2020). Desarrollo organizacional en la gestión municipal. $\begin{array}{lllll}\text { Ciencia Latina } & \text { Revista } & \text { Multidisciplinaria. } & 4 & \text { (2) }\end{array}$ https://www.ciencialatina.org/index.php/cienciala/article/view/133/153

Arévalo, F. y Delgado, J. (2020). Evaluación según modernización del Estado en la gestión municipal, 2020. Ciencia Latina Revista Científica Multidisciplinar, 4(2), 914-935. https://doi.org/10.37811/cl_rcm.v4i2.131

Alonso, M. (2020). Repensar la acción pública local desde nuevos modelos de gestión administrativa. Revista De Estudios De La Administración Local Y Autonómica. Nueva época, (14), 49-68. https://doi.org/10.24965/reala.i14.10808

Armas, G. (2018). La gestión de servicios municipales y su impacto en el desarrollo local. Caso municipalidades de la provincia de Heredia, Costa Rica. Revista Centroamericana de Administración Publica. 1 (74) 146-156. https://icap.academia.edu/RCAP

Beltrán, O. (2005). Revisiones sistemáticas de la literatura. Asociaciones Colombianas de Gastroenterología, Endoscopia digestiva, Coloproctología y Hepatología.

Casiano, D. y Cueva, E (2020). Gestión municipal, niveles de percepción y confianza: el caso para el distrito de Chachapoyas, Amazonas (Perú) 2019. ACADEMO-Revista de Investigación en Ciencias Sociales y Humanidades 7(2), 157-165. https://revistacientifica.uamericana.edu.py/index.php/academo/article/view/403

Carrera, L. y Galán, V. 2020. Iniciativa Municipal de Desarrollo Local: una opción para la producción cunícula Anuario. Facultad de Ciencias Económicas y Empresariales 2(21). https://repositorio.uho.edu.cu/handle/uho/6650?show=full.

Coelho, R., Guth, F. y Loureiro, M. (2020). Capacidades del gobierno municipal y desarrollo humano local en Brasil. Revista de servicio público, 71 (4), 778-808. https://doi.org/10.21874/rsp.v71i4.4524

Cordero, J. (2018). El gobierno municipal. ¿Promotor del desarrollo local? El caso del municipio semiurbano de $\mathrm{Cd}$. Ixtepec, Oaxaca. Estudios sociales. Revista de 
alimentación contemporánea y desarrollo regional, 28 https://doi.org/10.24836/es.v28i52.575.

De Armas, R. Tamayo, N. y Santos, M. (2017). Población, territorio y gestión para un desarrollo local sustentable. Revista Novedades en Población 13 (26) 166-175. http://scielo.sld.cu/scielo.php?script=sci_arttext\&pid=S181740782017000200013\&lng=es\&tlng=en.

Dvoryadkina E. y Belousova, E. (2020). Tendencias del desarrollo de las regiones municipales en el espacio económico nacional. Cambios económicos y sociales: hechos, tendencias, $\quad$ pronóstico, $13 \quad$ (1), 87-105. http://esc.vscc.ac.ru/article/28467?_lang=en DOI: $\underline{10.15838 / \text { esc.2020.1.67.5 }}$

Díaz, M. y Fernández, A. (2020). Gestión de gobierno, educación superior, ciencia, innovación y desarrollo local. Retos de la Dirección, 14(2), 5-32. http://scielo.sld.cu/scielo.php?script=sci_arttext\&pid=S2306-

91552020000200005\&lng=es\&tlng=es.

Flores, H. Gil, M. Ipaguirre, E. y Altavilla, C. (2018). Las decisiones del gasto público y el rol de los municipios en el desarrollo local en Argentina: Un abordaje desde la autonomía municipal y los actores sociales y políticos. Revista Terra de desarrollo local, $\quad 5(23) \quad$ 1-23. $\quad$ https://ojs.uv.es/index.php/TERRA/article/view/10894 https://ri.conicet.gov.ar/handle/11336/94552.

García, B. y Bartocci, L. (2019). Propuesta de indicador de eficiencia de la gestión pública municipal en la promoción del desarrollo local. Interacciones (Campo Grande) 20 (3). https://doi.org/10.20435/inter.v0i0.1831.

Gaviria, R. y Delgado, M. (2020). Mejora de los servicios públicos en el fortalecimiento de la gestión municipal. Ciencia Latina Revista Científica Multidisciplinar, 4(2), 1241-1255. https://doi.org/10.37811/cl_rcm.v4i2.151.

Gorina, A., Martín, M., Alonso, I y Gorina, N. (2018). Retos del desarrollo local en Cuba. Estudio de caso en el municipio Contramaestre. Batey. Revista Cubana de Antropología Sociocultural (ISSN 2225-529X), 11(3), 89-114. http://www.revistabatey.com/index.php/batey/article/view/226/152.

Ladillinsky, A. (2020). Resiliencia urbana y desarrollo local: planificación de la gestión municipal. Revista Perspectivas de Políticas Públicas. (10) 9 http://revistas.unla.edu.ar/perspectivas/article/view/3326. 
López, R., Ayala, D. y Arellanes, Y. (2017). Gobernabilidad democrática y desarrollo local sustentable. Economía y Sociedad, XXI (36),61-75 https://www.redalyc.org/articulo.oa?id=51052064004..

Martínez, C., Martínez, K., Martínez. L. y Velasco, A. (2020). Relación entre la gestión pública y el desarrollo local sustentable de las ciudades de Oaxaca, 2000-2017. Revista iberoamericana de estudios municipales, (22), 155-187. https://dx.doi.org/10.4067/S0719-17902020000200155.

Miranda, T., Machado, H., Lezcano, J., Suset, A., Oropesa, K., Tirado, F., Lamela, L. y Montejo, I. (2019). Aprendizajes en el proceso de gestión del desarrollo local en un $\begin{array}{llll}\text { municipio matancero. Pastos } \quad y \quad \text { Forrajes } & \text { 42(1), }\end{array}$ http://scielo.sld.cu/scielo.php?script=sci_arttext\&pid=S0864$\underline{03942019000100073 \& \operatorname{lng}=\mathrm{es} \& \mathrm{t} \operatorname{lng}=\mathrm{pt} .}$.

Montecinos, E. y Contreras, P. (2019). Participación ciudadana en la gestión pública: Una revisión sobre el estado actual. Revista venezolana de Gerencia 24(86) 341-362. https://www.redalyc.org/articulo.oa?id=29059356004.

Polanco, A. y Caballero, M. (2020). Fortalecimiento de las capacidades de los actores locales para la gestión del desarrollo local desde el punto de vista cultural. Revista Retos de la dirección, 45-67. http://scielo.sld.cu/scielo.php?script=sci_arttext\&pid=S2306-

91552020000100045\&lng=es\&tlng=.

Quispe, G., Ayaviri, D. y Maldonado, R. (2018). Participación de los actores en el desarrollo local en entornos rurales. Revista de Ciencias Sociales (RCS) XXIX (3). 62-82. https://dialnet.unirioja.es/servlet/articulo?codigo $=7025048$

Sánchez, F., Moschini, M., Guevara, J., Camones, F., Loayza, S. y Uribe, Y. (2020). Promoviendo la financiación pública y desarrollo local municipal. Revista Inclusiones, revista de Humanidades y Ciencias Sociales 1 (7). https://revistainclusiones.org/index.php/inclu/article/view/1204.

Torres, C. (2018). Modelo para la gestión de políticas territoriales de desarrollo local a escala municipal en Cuba. Revista Anales de la Academia de Ciencias de Cuba 8(1) 1-7 http://revistaccuba.sld.cu/index.php/revacc/article/view/405.

Vargas, M., Fernández, L., Quiroz, J. y Cacho, A. (2020). Gestión municipal y respuestas frente al impacto del COVID 19 -municipalidades de la zona alto andina, departamento de Lambayeque. Revista Científica Pakamuros 8 (4). 
105-115.

https://www.researchgate.net/publication/348092644_Gestion_municipal_y_respue stas_frente_al_impacto_del_COVID_19_-

_municipalidades_de_la_zona_alto_andina_departamento_de_Lambayeque

Zorrilla, S. (1993). Introducción a la metodología de la investigación. Aguilar León y Cal Editores. 